\title{
Heterogeneidades narrativas na antropologia contemporânea: perspectivas latino-americanas
}

Dol

http://dx.doi.org/10.11606/ 1678-9857.ra.2021.184485

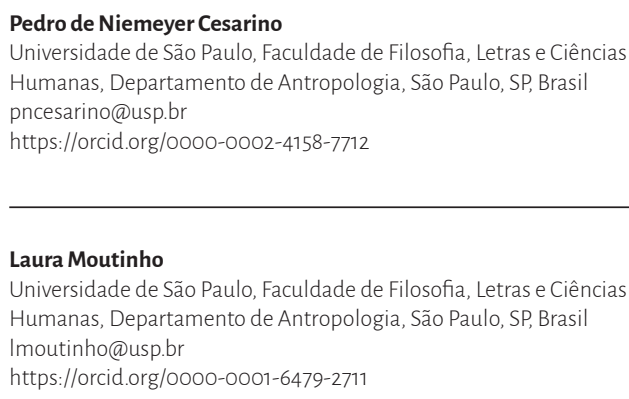

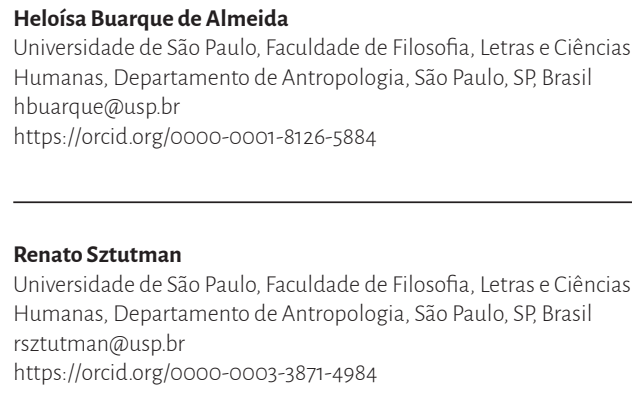

Universidade de São Paulo, Faculdade de Filosofia, Letras e Ciências Humanas, Departamento de Antropologia, São Paulo, SP, Brasil rsztutman@usp.br

https://orcid.org/0000-0003-3871-4984

O presente número da Revista de Antropologia reúne um conjunto significativo de artigos em espanhol e de estudos voltados a realidades latino-americanas. Tais publicações parecem consolidar uma perspectiva antropológica do Sul voltada a desafios etnográficos que, se pertencem a campos diversos de pesquisa, partilham, contudo, desafios teóricos e políticos similares. Destacam-se, por exemplo, as relações conflitosas entre processos de desenvolvimento econômico e suas decorrentes desterritorializações de modos de relação e de conhecimentos locais. Vistos sob uma ótica política, tais conhecimentos vão sendo simetrizados às narrativas produzidas pela academia ou, ainda, são concebidos como estratégias de resistência aos cerceamentos da vida, do apagamento da subjetividade, dos nexos de parentesco, de dinâmicas interespecíficas, da constituição do corpo e do erotismo, da relação de marginalização no espaço urbano.

É assim que metodologias diversas tais como a etnografia multissituada ou a etnografia em ambientes on-line encontram outras mais tradicionais para, via perspectivas analíticas distintas, refletir sobre as transformações sociais contemporâneas marcadas pelos fluxos do capital. Deparamo-nos, contudo, com o contrário da planificação que se esperaria ser decorrente das imposições econômicas e políticas hegemônicas, pois os estudos ora apresentados apontam, antes, para heterogeneidades narrativas, epistemológicas e subjetivas complexas, perseguidas com densidade nas pesquisas em questão. Trata-se de um claro estímulo à tarefa da antropologia em uma contemporaneidade em ruínas, na qual cada vez mais as condições do trabalho intelectual encontram-se desafiadas pela precarização e mercantilização; condições essas não menos adversas do que aquelas em que vivem muitas das pessoas com as quais trabalhamos e a partir das quais projetamos as possibilidades de uma política do pensamento. 
Adriana Peñafiel e Guilherme Radomsky, em “'Água é vida': política, memória e experiência nos conflitos em torno da mineração em Cajamarca, Peru" tratam da luta pela água e pela vida, em Cajamarca, Peru, e sua relação com projetos de mineração. Exploram os desafios da relação entre o desenvolvimento e seu confronto com lutas e manifestações pelo direito à vida e por modos de existência relacionados à integração entre pessoas e paisagens convertidas em recursos pela exploração mineradora. Gabriela Schiavoni, em "Consanguinizar y Afinizar. La domesticación de los animales, las plantas y los humanos en las acciones de desarrollo" estuda as relações de familiarização entre pequenos agricultores, animais de criação e espécies comestíveis na região de Misiones, Argentina, na tentativa de compreender as relações desenvolvidas por uma "taxonomia geral do vivente" a partir de relações de consanguinidade e de afinidade pensadas pela etnologia americanista de Viveiros de Castro e outros autores. O processo de consanguinização de cultígenos e de animais, contudo, é visto por Schiavoni pela fricção causada entre a sua trama local, estabelecida pelas relações de parentesco entre humano e não humano, e as planificações impostas pelas modificações genéticas e outras tecnologias mobilizadas pelo desenvolvimento econômico.

Em "Políticas de la Música Bailable en Colombia: una aproximación al regionalismo 'paisa' a partir de sus estéticas musicales, dancísticas y festivas", América Larranín, através de uma minuciosa etnografia multissituada, mostra como a forma 'paisa' dissemina-se em Antioquia, na Colômbia, através de uma estética musical de implicações políticas responsável pela consolidação da imagem nacional da pessoa empreendedora, católica, conservadora, associada à economia agrícola e a certa construção da branquitude oposta à presença indígena e negra. Responsável por vitórias políticas da direita colombiana, tal região é também aquela que consolida uma identificação coletiva associada a determinados gêneros musicais e suas danças associadas à cultura nacional. Em "El camino y el caminar: fuentes históricas de los rarámuri de la Sierra Tarahumara, México", Isabel Martinez considera os registros territoriais como uma fonte para a história rarámuri (Tarahumara do Norte do México), constituindo uma forma de produção de conhecimento concreto através do espaço que se choca com a planificação da região pela indústria madeireira e outros projetos de desenvolvimento. Trata-se assim de compreender a produção da história do ponto de vista rarámuri a partir de uma perspectiva simétrica essencial para a luta por direitos e para a própria possibilidade de compreensão de uma história não mais unilateral, mas compartilhada.

“'Eu tô vivo e isso aqui é minha vida agora': produção de territórios e condições de existência no cotidiano de uma prisão", de Sara Vieira Antunes, compreende o corpo do sujeito aprisionado como seu último território de resistência frente à destituição da subjetividade, com base em uma etnografia realizada em penitenciária feminina da cidade de São Paulo, Brasil. Em vez de se voltar ao estudo de prisões pela dinâmica do crime, Antunes se dedica à compreensão das estratégias de resistência, 
de territorialização e de constituição da vida. Em "Interações, trilhas e caminhos de uma cidade em fluxo: etnografia na Cracolândia”, Ygor Alves e Pedro Paulo Comes Pereira dedicam-se a compreender o que atrai pessoas para o "fluxo" da Cracolândia, cena urbana de uso do crack situada na cidade de São Paulo, Brasil, vista pelos autores como uma malha relacional de enlaces e desenlaces, inacabada, marcada pela movimentação, pelo acontecimento e entrelaçamento de pessoas e materiais que definem "malocas", "cachimbos" e "caminhadas", noções constitutivas de uma complexa relação entre espaço urbano e ser humano.

Lorena Rúbia Pereira Caminhas, em "Webcamming erótico comercial: nova face dos mercados do sexo nacionais", analisa o universo de constituição de narrativas e da subjetividade deste mercado erótico tornado presente no Brasil dos últimos anos. Trata-se de mais um campo desafiador de estudos dedicado às relações em transformação entre virtualidade e realidade e seus efeitos decorrentes nas relações comerciais e subjetivas. Aline Lopes Rochedo, por sua vez, em "Individualidade e produção do feminino através da moda urbana Lolita", explora a construção da feminilidade através da moda Lolita, criada no Japão e expandida para outros países, entre os quais o Brasil dos anos 1990 e 2000. Elaborado em grande parte através da etnografia on line, o artigo é outra demonstração dos desafios da pesquisa etnográfica em ambientes digitais que, cada vez mais, demonstram suas capacidades analíticas para a compreensão de dinâmicas de gênero, entre outras.

Em um ambiente distinto, mas ainda assim dedicado a explorar divergências discursivas, Carla Semedo, em "Mobilidades e territórios impensáveis. Contranarrativas e afetos de cabo-verdianos nas roças de São Tomé e Príncipe", mostra como São Tomé e Príncipe foi sendo construído como território marcado por suas diferenças e mobilidades através da culinária, que produz diferenças entre práticas e existências africanas e a europeização de costumes. Na tentativa de produzir alternativas à história desumanizante através da qual são concebidos, os cabo-verdianos de São Tomé produzem então contranarrativas muitas vezes ignoradas pelas imagens hegemônicas de seu país.

Por fim, Ypuan Garcia, em “A 'libertação' entre cristãos e o conceito antropológico de ritual", explora o confronto entre as abstrações referentes ao conceito antropológico de ritual (marcadamente associadas à noção de padrão) e os modos de pensar de católicos carismáticos de São Paulo, Brasil, especialmente no que se refere à noção de libertação derivada de tal contexto etnográfico, marcada pela indeterminação, insondabilidade e outras características associadas à experiência do divino.

Pedro de Niemeyer Cesarino é professor doutor do Departamento de Antropologia da FFLCH/USP e editor-chefe da Revista de Antropologia. Pulicou Oniska - poética 
do xamanismo na Amazônia (Ed. Perspectiva/FAPESP, 2011), Quando a Terra deixou de falar - cantos da mitologia marubo (Ed. 34, 2013), entre outros livros e artigos.

Heloisa Buarque de Almeida é professora doutora no Departamento de Antropologia e no PPGAS-USP, e membro do NUMAS - Núcleo de Estudos dos Marcadores Sociais da Diferença. Foi Visiting Fellow na London School of Economics com bolsa FAPESP, é e membro do Conselho Científico da Associação Brasileira de Antropologia. É bolsista de produtividade do CNPq, e tem apoio da FAPESP.

Laura Moutinho é professora Associada (Livre-Docente) do Departamento de Antropologia e do PPGAS ambos da USP. Pesquisadora do NUMAS/USP. Coordena a Comissão Projeto Editorial da ABA. Publicou o livro Razão, Cor e Desejo: uma análise dos relacionamentos afetivo-sexuais inter-raciais no Brasil e África do Sul, Editora Unesp: São Paulo, 2004, graças ao prêmio EDUSC\ANPOCS para melhor tese de doutorado| edição 2003. É bolsista produtividade nível $1 \mathrm{D}$ do CNPq e tem apoio da FAPESP.

Renato Sztutman é professor do Departamento de Antropologia e do Programa de Pós-Graduação em Antropologia Social (PPGAS) da Universidade de São Paulo. É bolsista produtividade do CNPq. Autor do livro O profeta e o principal: a ação política ameríndia e seus personagens (Edusp/ Fapesp,2012).

\section{REFERENCIAS BIBLIOGRÁFICAS}

ALVES, Ygor Diego Delgado; PEREIRA,

Pedro Paulo Gomes. 2021. "Interações, trilhas e caminhos de uma cidade em fluxo: etnografia na Cracolândia". Revista de Antropologia, 64(1): e184481. http://dx.doi. org/10.11606/1678-9857.ra.2021.184481

ANTUNES, Sara Vieira. 2021. "'Eu tô vivo e isso aqui é minha vida agora': produção de territórios e condições de existência no cotidiano de uma prisão". Revista de Antropologia, 64(1): e184480. http://dx.doi. org/10.11606/1678-9857.ra.2021.184480

CAMINHAS, Lorena Rúbia Pereira. 2021. "Webcamming erótico comercial: nova face dos mercados do sexo nacionais".
Revista de Antropologia, 64(1): e184482. http:// dx.doi.org/10.11606/1678-9857.ra.2021.184482

GARCIA, Ypuan. 2021. 'A 'libertação' entre cristãos e o conceito antropológico de ritual". Revista de Antropologia, 64(1): e182376. http:// dx.doi.org/10.11606/1678-9857.ra.2021.182376

LARRAÍN, América. 2021. "Políticas de la Música Bailable en Colombia: una aproximación al regionalismo 'paisa' a partir de sus estéticas musicales, dancísticas y festivas". Revista de Antropologia, 64(1): e184477. http://dx.doi. org/10.11606/1678-9857.ra.2021.184477

PENÃFIEL, Adriana Paola Paredes; RADOMSKY, Guilherme Francisco Waterloo. 2021. "Água é vida: política, memória e experiência 
EDITORIAL | Pedro de Niemeyer Cesarino, Laura Moutinho, Heloísa Buarque de Almeida e Renato Sztutman | Heterogeneidades narrativas

na antropologia contemporânea: perspectivas latino-americanas

nos conflitos em torno da mineração

em Cajamarca, Peru". Revista de

Antropologia, 64(1): e184476. http://dx.doi.

org/10.11606/1678-9857.ra.2021.184476

RAMIREZ, Maria Isabel Martinez.

2021. "El camino y el caminar: fuentes históricas de los rarámuri de la Sierra

Tarahumara, México". Revista de

Antropologia, 64(1): e184479. http://dx.doi. org/10.11606/1678-9857.ra.2021.184479

ROCHEDO, Aline Lopes. 2021.

"Individualidade e produção do feminino através da moda urbana Lolita". Revista de Antropologia, 64(1): e184475. http://dx.doi. org/10.11606/1678-9857.ra.2021.184475
SCHIAVONI, Gabriela. 2021. "Consanguinizar y Afinizar. La domesticación de los animales, las plantas y los humanos en las acciones de desarrollo". Revista de Antropologia, 64(1): e178185. http://dx.doi. org/10.11606/1678-9857.ra.2021.178185

SEMEDO, Carla. 2021. "Mobilidades e territórios impensáveis. Contranarrativas e afetos de caboverdianos nas roças de São Tomé e Princípe". Revista de Antropologia, 64(1): e184478. http:// dx.doi.org/10.11606/1678-9857.ra.2021.184478 